\title{
A integração cultural do japonês na cultura brasileira: A experiência da Colônia de Ivoti
}

\author{
Geraldine Alves dos Santos \\ Johannes Doll \\ Tomoko Kimura Gaudioso
}

\section{Introdução}

No Brasil, os imigrantes japoneses chegaram a partir do início do século, em 1908, depois que o governo italiano passou a desestimular a emigração para o Brasil, devido às dificeis condiçôes de vida no país. Para o governo japonês era mais interessante enviar seu povo para o Brasil do que para os Estados Unidos, onde eram discriminados. Inicialmente, os japoneses se estabeleceram no Estado de São Paulo, mas também se espalharam por outras regiões do país. No Rio Grande do Sul, os japoneses chegaram em duas ondas imigratórias, a primeira vinda de São Paulo, em 1924, e a segunda ocorreu entre 1955 e 1963 , momento em que os japoneses vieram diretamente para o Estado (FLORES, 1997). No Btasil, os japoneses dedicaram-se, no início, predominantemente à atividade agrária, desenvolvendo não apenas a a tividade, mas também a tecnologia para a produção e a sua comercialização. Eles propiciaram ao brasileiro a diversificação dos tipos de verduras comercializadas. Contribuíram também para a cultura brasileira através da produção de flores como o crisântemo, na utilização da comida macrobiótica, na prática de artes marciais e com a "delicadeza simbólica da Ikebana" como ressalta Flores (1997, p. 189). Segundo a definição de Diégues (1980), o japonês que veio para o Brasil é do tipo "pareano", ou seja, oriundo das "classes inferiores do Japão" (p.139-140). Conforme este auror sua religião é predominantemente budista ou xintoísta. Existem ainda outras religiōes, inclusive a católica, mas em menor número; de qualquer maneira; mantém seus rituais em relação a cerimônias como casamentos e funerais. Os imigrantes japoneses mantiveram muitos dos seus traços culturais, principalmente em relação à estrutura familiar, que é do tipo patriarcal e monogâmica (DIÉGUES, 1980). 
A integração do imigrante japonês na cultura brasileira teve dois empecilhos que os fizeram muitas vezes isolar-se em colônias nipônicas. Estes elementos dos seus valores culturais foram o trabalho e a hierarquia. "Suas tradições milenares, o forte nacionalismo e o orgulho de pertencer a uma das potências mundiais dificultam sua integração com os brasileiros" (FLORES, 1997, p. 189).

Vátias colônias nipônicas formaram-se por todo Brasil. Nosso estudo foi centrado na Colônia de Ivoti, no Estado do Rio Grande do Sul. No dia dois de julho de 1966, vinre e seis familias japonesas instalatam-se na Vila Palmares no município de Ivoti e foram direcionadas pelo sr. Sasada, professor e formado em agronomia no Japão. Essas famílias eram consideradas e aceitas pela cultura alemã predominante na região por terem o mesmo espírito de capricho e trabalho. Inicialmente, os imigrantes japoneses trabalharam na criação de frangos e, posteriormente, na plantação de morangos e uva. Como relata Patro (s.d.) esta foi uma época próspera com a construção de casas de alvenaria e a compra de carros. Porém, com o decorrer do tempo, aparecetam dificuldades na comercialização dos produtos, e a colônia passou a se dedicar ao plantio do kiwi. Naturalmente, como a autora telata, o racismo, durante um born tempo, afastou os japoneses do convivio social integral com os alemães. Foram as crianças, ao freqü̈entarem as escolas, que promoveram o início da integração efetiva. Atualmente, algumas pessoas ainda possuem dificuldade para falar o português, principalmente, os idosos. Por outro lado, os casamentos entre japoneses e alemães integraram as etnias e as manifestações culturais durante as festas e a integração de religiões garantiram a convivência harmoniosa entre estes povos que tinham o objetivo comum de reconsrruir suas vidas em uma nova terra.

Transcorridos rantos anos do estabelecimento dos japoneses no Brasil e, especificamente, na colônia de Ivoti, percebe-se que o japonês transformou muitas coisas na cultura brasileira, da mesma maneita que a sua cultura nipônica foi modificada. Mesmo existindo ainda algumas dificuldades, percehemos que o japonês conseguiu criar e administrar o seu espaço na cultura brasileira.

\section{Método}

Realizamos na Colônia Japonesa de Ivoti, situada no Esrado do Rio Grande do Sul, Brasil, uma pesquisa descritiva com 20 homens japoneses de idades que vatiaram dos 21 aos 84 anos de idade, abrangendo a primeira geração de imigrantes (isseis), segunda geração (nisseis) e a rerceira geração (sansseis). Foram realizadas entrevistas semi-estruturadas individuais, abordando temáticas jurídicas, lingüística e culturais. 
Tabela 1. Distribuição segundo geração de imigração e idade

\begin{tabular}{|l|c|c|c|c|c|c|}
\hline & \multicolumn{2}{|c|}{$1^{\wedge}$ geração (isseis) } & \multicolumn{2}{c|}{$2^{a}$ geração (nisseis) } & \multicolumn{2}{c|}{$3^{a}$ geração (sansseis) } \\
\hline Faixa etária & \multicolumn{2}{|c|}{$50-84$ anos } & \multicolumn{2}{|c|}{$31-44$ anos } & \multicolumn{2}{|c|}{$21-30$ anos } \\
\hline Nacionalidade & japonesa & brasileira & japonesa & brasileira & japonesa & brasileira \\
\hline Número de pessoas & 11 & 1 & 0 & 6 & 0 & 2 \\
\hline
\end{tabular}

\section{A importância da educação na cultura nipônica}

O histórico da emigração japonesa, como referido por Staniford (1973), demonstra que a escolha pela busca de novas terras além-mar ocorreu em função de dois principais motivos: 1. alternativa para as pessoas que não eram os sucessores e conseqüentemente não tinham uma herança garantida; 2 . as pessoas que já estavam empobrecidas e não possuíam nenhuma outra alternativa no país de origem. Nesse sentido, as pessoas que imigraram possuíam um grande desejo de verem seus descendentes comı uma sólida formação acadêmica para que atingissem posições sociais e econômicas mais estáveis. As pessoas entrevistadas em nosso estudo demonstram preocupação em relação aos estudos, principalmente com os mais jovens, para que esses se desenvolvam. Não necessariamente que saiam da colônia, mas que alarguem os seus horizontes. Entretanto, mesmo com o estudo, a maioria das 20 pessoas entrevistadas mantém as suas atividades relacionadas à agricultura. Este vínculo com a terra, que em muiros casos foi trazido do Japão, mantém-se e configura uma relação com as origens culturais deste grupo.

Os japoneses percebem que a maneira mais eficaz de garantir um futuro promissor para a família está no estudo, que representa uma das características típicas da cultura tradicional nipônica (SCHADEN, 1973). Por isso, exigem tanto dos filhos e valorizam suas conquistas. Necessariamente não esperam que os filhos saiam do meio rural, ao contrário, mas buscam o sratus que thes garantirá mais respeito social e financeiro.

Perceber-se como aponta Staniford (1973) que os imigrantes, apesar de rrazerem muitas características de personalidade típicas dos japoneses, se diferenciam dos mesmos pelo espírito de reação e pela busca por melhores condições. Estas pessoas sofreram muitas dificuldades para melhorarem de vida e demonstram em todos os elementos de sua cultura que não são conformados, muito pelo contrário, são guerreiros em busca de novos horizontes.

\section{Aspectos jurídicos dos imigrantes japoneses}

A maioria das pessoas entrevistadas, da primeira geração, chegaram ao Brasil após a II Guetra Mundial, através do sisterna kousei kazoku, uma forma de imigração pot família. Na época só era permitida a entrada no país das famílias que possuíssem, no mínimo, duas pessoas com condição de trabalhar (importação de mão-de-obra). Os solreiros que quisessem imigrar para o Brasil declaravam-se como membro da família, assim obtendo o visto de entrada. No caso das pessoas entrevistadas, somente uma pessoa declarou ter entrado no país com esse sistema na qualidade de ascendente da família. 
Quanto à questão de deixar o filho primogênito no Japão para preservar a genealogia da famúlia no país de origem, nenbum dos entrevistados realizou tal ato. Em relação à nacionalidade, a pesquisa mostrou que os imigrantes mantêm fotte vínculo com o país de origem. Com uma única exceção, todos os isseis mantêm nacionalidade japonesa. Em relação ao registro dos filhos para obter a nacionalidade japonesa, quatro registraram todos os seus flhos, um registrou três dos quatro filhos, dois registraram apenas um filho e quatro não registraram nenhum de seus filhos. Portanto, mais de $63,5 \%$ dos entrevistados mostraram a intenção de manter o vínculo da geração seguinte com o pais de origem através da obtenção de nacionalidade. Isto ocorte porque a legislação japonesa permite a dupla nacionalidade desde que seja registrado o nascimento do filho no Corpo Consulart.

Em relação ao registro de casamento no Corpo Consular, o hábito de registrá-lo é mais acentuado até a década de 70 (1968 - 1975). Com exceção de um registro de casamento em 1980 , a partir dos anos 80 , os quatro casamentos posteriores não são mais registrados. Por outro lado, um entrevistado casou-se no Brasil e no Japão, via Consulado, caracterizando a bigamia com a mesma pessoa, o que fururamente poderá gerar conflito de cunho jurídico no que tange ao direito sucessório, previdenciário, etc.

Os óbitos são geralmente registrados. Somente uma pessoa enrrevistada mencionou o não cadastramento de um familiar falccido, o que resulta na permanência do mesmo no cadastro da familia, no koseki tobon, como nembro vivo.

Em relação à propriedade, todos possuem imóveis no Brasil mas ninguém possui bens no Japão. Este fenômeno chama a atenção tendo em vista que a cultura japonesa enfatiza o "sistema de casas".

O código civil japonês, nos capitulos referentes ao direito de família e sucessões, estabelece uma desigualdade entre homens e mulheres como concessão de direito à herança ao fllho primogênito ou ao filho adotivo sucessor da família ${ }^{2}$. Quanto ao tegistro de pessoas físicas, o sistema de registro de família adotado determinava atribuir sobrenome ou nome de família a todos os cidadãos do pais, indistintamente das classes, unificando o nome da esposa ao nome do marido ${ }^{3}$, garantindo, de certa forma, a sucessão que ocorreria somente

'Pela legislação japonesa, o individuo com dupla nacionalidade deve optar pela nacionalidade que line aprouver ao atingir a maioridade.

2 A sucessão visa principalmente a perpetuação da linhagem e năo somente à herança do patrimônio. O filho adotivo com objetivo de suceder-se na linhagem familiat no Código Civil antetior era denominado de yarbishi, diferenciando-se do yoshi, os demais filhos adotivos. É interessante observat que os japoneses, apesar de dâr importância à consangüinidade, às vezes adotavam filhos sem laços de parentesco. KANDAICHI, Haruhiko et alii, org. Nibong daijiten, Tóquio: ,Kodansha, 1989, p.2021.

${ }^{3}$ Segundo Noriko Mizuno (2001), da Universidade de Tohoku, os indivíduos que possuíam sobrenome até o firn do periodo Edo eram em torno de $6 \%$ da população total, época em que as mulheres adotavarn o nome de solteira mesno após o casamento. A Reforma Meiji estabeleceu sistema de registro de famíla obrigando às mulheres a adotar o sobrenome da familia que a mulher pertencia. Assim, quando muther casava, desvinculavase da familia dos pais biológicos ou mesmo adotivos. Assim, era the permitida retornar à sua casa natal somente uma vez por ano, no periodo dos finados, em agosta. Ver tb. MIZUNO, Noriko. Minpon ga kazokin wo kinitsu shite isseiki. In: Manabi no mori. Sendai: University of Tohoku, 2001. N"1G. Ver também GAUDIOSO, Tomoko Kimura. The wotnan s rights in the juptanese sacity: its historical perspective. In: Revista da Faculdade de Direito da Universidade Federal do Rio Grande do Sul, Edição Especial . Porto Alegre:UFRGS. Set/2002. 
por linha masculina. Depois da II Guerra Mundial, com a refotmulação do Código Civil japonês, em 1947, o conceito de "família" é excluído de seus textos.

Em relação a direito das sucessões, o novo código contemplou-o no Livro V, que compreende o art. 882 e os seguintes. ${ }^{4}$ Porém, apesar de conquistar a igualdade, no que tange a tradição, os filhos primogênitos ainda se privilegiam em herdar os bens deixados por pais. A possibilidade de nomear um terceiro como herdeiro do oráculo da família (artigo 897) assim como permitir a habilitação à herança da pessoa que cuidou do falecido durante sua vida igualmente são peculiaridades da legislação japonesa.

\section{Art. 904-2-(da doação)}

$\$ 1^{\circ}$. Se entre co-herdeiros houver aquele que colaborou especialmente na manutenção ou aumento de bens de herança, pelo auxílio financeiro ou pelo trabalho nas arividades do falecido ou cuidá-lo na enfermidade, por consentimento dos co-herdeiros, esse valor será subtraído dos bens deixados. O ordenamento jurídico japonês garante a participação à herança da pessoa que colaborou com o falecido durante a vida, assim:

(...) se reconhecer como adequado, a Corte de Famillia poderá conceder todo ou parte do saldo de herança para aqueles que a solicitarem desde que tenha havido relação especial com o falecido(..) (CÓDIGO CIVIL JAPON $\hat{E S S}$, art. 958 - 3)

Sob a perspectiva da sociologia jurídica, é interessante o comportamento dos imigrantes japoneses face as diferenças encontradas na concepção do conccito de família e de sucessões entre o Japão e Brasil e sua repercussão no campo jurídico, o que pode ser observado até o presente momento na pesquisa de campo.

\section{Costumes e Identidade}

Os imigrantes japoneses demonstram, como expõe Staniford (1973), quatro características principais de personalidade. "Em primeiro lugar, a ausência de fé em uma natureza pródiga; $\mathrm{em}$ segundo, baixa tolerância à frustração; em terceiro, uma percepção negativa da autoridade; e, finalmente, uma forte dose de autoconfiança" (p. 44). A partir desta concepção torna-se mais compreensivel uma série de achados de nosso estudo que enfocam os costumes e a identidade do imigrante japonês no Brasil.

Mesmo no Brasil, as pessoas da Colonia de Ivoti, sentem diferenças regionais. A maioria não se sente à vontade em Porto Alegre, pois considera perigoso e poluido. Porém, as pessoas mais jovens que possuem um contato mais freqüente com a capital possuem

" Conforme Nuriko Mizuno, o antigo dircito de familia, que vigorou de 1898 a 1947, apoiava-se no "sistema de casas". Qualificado como feudal, sob a atual Constituição de 1946, que prevê a dignidade do individuo e a igualdade de sexo na vida familiar (art. 24), o legislador de 1947 abrogou esse sistema e estabeleceu igualdade entre herdeitos. MIZUNO, Noriko. Ob. Cit. p. 32. 
facilidade de adaptação. As pessoas mais velhas se integraram tão bem à colônia que sentem necessidade da segurança encontrada naquela região e do fato da colônia ainda manter culturalmente uma integração mais estável em relação às famílias e também à cultura de maneira mais ampla. A cultura brasileira atrai os japoneses principalmente em função da amizade, do humanismo, da liberdade, do otimismo, da alegria, das festas e do esporte. Por outro lado o que o grupo entrevistado observa como desconfortante na cultura brasileira é o descompromisso, os políticos, os roubos, a pobreza, a ausência de segurança, a falta de respeito humano e a mania de levar vantagem.

Fazendo um contraponto com a cultura brasileira os japoneses enrtevistados levantaram que em relação à cultura japonesa o que eles mais apreciam é a seriedade das pessoas, principalmente em relação ao trabalho, a curiosidade, a educação, o silêncio, o comportamento calmo, o transporte fácil, a dança, a música, o esporte e principalmente a tradição. Na questão sobre o que não gostam eles levantaram a excessiva seriedade, timidez, meticulosidade, falta de liberdade de expressão, mesquinhez e falta de solidariedade ao japonês. É interessante ressaltar que para essa questão, 12 pessoas consideraram melhor não responder ou não encontraram nada de ruim. Com isto reforçam o comportamento típico do imigrante e da cultura japonesa de manter as tradições sem criticá-las.

De todos os sujeitos entrevistados 9 consideram-se mais brasileiros do que japoneses, um dos sujeitos refere-se não apenas mais brasileiro como especificamente gaúcho e outro refere a questão de querer de qualquer maneira preservar os costumes japoneses. Portanto não existe uma negação da origem japonesa, mas uma adaptação e respeito à nova pátria, principalmente, na concepção dos mais jovens. As pessoas mais velhas consideram-se de maneira geral mais japonesas. No entanto 5 pessoas conseguem realizar a reflexão de que são tão brasileiras quanto japonesas. Elas referem este pensamento através de expressões como a de ser japonês por ter nascido no Japão, mas de também gostar de ser brasileiro. Outra percepção que se evidencia é o rótulo de ser brasileiro no Japão e japonês no Brasil. Essas pessoas que se identificam com a dupla nacionalidade são as que nasceram no Japão, mas vieram muito novos para o Brasil, não querendo fazer escolhas sobre suas preferências, pois elas se definem conforme a situação que se apresenta no cotidiano.

\section{Familia e Cultura}

As familias continuam se mantendo extensas, mesmo as pessoas mais novas mantêm a tradição de viverem com os pais, avós ou sogros. Outro dado interessante a ser destacado e que não permite que eles cortem as relações com o Japão é que além do fato da maioria já ter ido ao Japão também possuem vários parentes que residem lá permanente ou temporariamente. Nem todas as famílias estão unidas por questões de estudo, de trabalho ou mesmo de casamento. Mas nota-se que a familia que teside no mesmo lugar mantém como hábito os encontros durante as refeições e nas datas mais importantes não dispensam os encontros como no natal, ano novo, aniversátios, casamentos, funerais. A família de maneira geral costuma trabalhar junto, mesmo os mais jovens que estudam longe costumam retornar no fim de semana para ajudar os pais. 
As famílias também se mantêm como um dos pontos centrais da cultura japonesa. Das pessoas entrevistadas dezessete são casadas, uma é viúva e duas são ainda solteiras devido à pouca idade. Não surgiu nenhum caso de separação neste grupo demonstrando que apesar de todas as dificuldades que este grupo passa eles se mantém coesos em relação à família. O fato dessas familias periodicamente se separarem em função das viagens para o Japão para conseguir uma fonte de renda extra não modifica a estrutura familiar. $O$ vínculo com o Japão é constante, apenas cinco pessoas não realizaram uma visita, mas gostariam de fazê-la para passear e conhecer o seu país de origem. Das vinte pessoas entrevistadas oito não teriam interesse em retornar ao Japão novamente em função de não gostarem do país em comparação ao Brasil e por ser muito cansativa a viajem. As outras doze pessoas demonstraram interesse em regressar ao Japão exatamente por não terem realizado ainda esta experiência, mas também por causa de familiares, pela falta de segurança no Brasil e principalmente pelo ponto de vista financeiro.

Uma das maiores dificuldades encontradas pelos imigrantes japoneses ao chegar no Brasil foi a língua, pois como refere Izumi (1973) não existe nenhuma afinidade entre o japonês e o português. Naturalmente nos primeiros tempos a demanda por falar o português rão foi tão intensa devido ao empenho que tiveram com o trabalho agrícola centrado, principalmente, na família. Mas com o decorrer do tempo as exigências se acentuam e eles precisam aprender a nova língua. Para a segunda geração esta ligação entre os idiomas ocorreu com um pouco mais de naturalidade. $O$ maior empecilho para o imigranre japonês em falar o português está centrado na concepção de que ela equivale ao "espírito japonês" (IZUMI, 1973).

Em nossa pesquisa identificamos que em relação à primeita língua dezoito pessoas responderam que foi a japonesa, apenas os mais jovens já aptenderam a falat o português. Embora todos falem as duas línguas não demonstram preferência, embora utilizem o português e o japonês. Pode-se considerar que o japonês é a língua que os atrela a cultura japonesa e conseqüentemente às suas origens e às pessoas mais velhas que representam o elo mais forte com a tradição. Porém, a língua portuguesa é o elemento que os integra com a sua vida atual, que lhes proporciona a segurança do futuro para si e para os seus descendentes. Assim não podem preferir uma ou outra língua, pois ambas possuem papéis centrais em suas existências.

O convivio dos mais jovens com os mais idosos, no conceito das famílias, propicia principalmente a manutenção da cultura japonesa através do exemplo do orgulho da descendência, o respeito aos antepassados e a manutenção da língua e dos costumes. Além disso, a manutenção das virtudes como a determinação, a autoconfiança, a assiduidade, 0 zelo à família e o respeito aos outros.

\section{Representações dos Idosos e Jovens na cultura brasileira e japonesa}

Segundo as pessoas entrevistadas o jovem no Brasil é visto como sendo bem tratado e o problema é que as famílias os deixam muito livres e incentivam a independência. Eles reconhecem que os jovens de hoje são diferentes, antes eram mais sérios e agota falta o respeito, são irresponsáveis, alćm do problema das drogas que tem que ser controlado. 
Mas também são vistas coisas positivas nos jovens como a alegria, a independência e os relatos apontam que os mais velhos respeitam esta independência. Os jovens que trabalham dentro da Colônia de Ivoti obedecem aos idosos e ajudam nas tarefas. Na concepção das pessoas entrevistadas o jovem deve receber mais atenção. Isto demonstra una necessidade constante de atenção ao jovem e também uma preocupação com a sua formação futura.

No Japão a juventude está sendo vista com muita preocupação, como refere Scott (2002), pois a segurança que eles deveriarn representar para os mais velhos está sendo abalada por uma série de elementos. Segundo os dados de nossa pesquisa o imigtante japonês no Brasil identifica o jovem no Japão com uma imagem mais estruturada em que os pais esperam a ascensão social dos filhos, existe proteção excessiva e os jovens são considerados o futuro do país e sofrem influência política. Mas eles também são visto como alegres. A educação é um dos pontos centrais que recai sobre os jovens onde desde cedo eles aprendem a disciplina e o tespeito Também existem as criticas normais das relações entre diferentes geraçöes, como o fato dos jovens estarem modernizados, liberais demais e importarem a cultura norte-americana pintando os cabelos de loiros. Portanto, observa-se que no Japão os jovens são vistos com melhor avaliação em função da educação formal que recebem, porém as críticas acabam recaindo sobre as diferenças que se estabelecem entre as faixas etátias que fazem parte do desenvolvimento normal.

O povo japonês, de acordo com o trabalho tealizado por Scott (2002), reflete as mesmas preocupações em relação aos jovens encontradas em nosso estudo. A superproteção éo ponto mais preocupante, pois consideram que os pais apresentan excesso de cuidado com os filhos. O sintoma dessa situação é o aparecimento dos "jovens rebeldes" que parecem estar se afastando das tradições nipônicas. O estudo de Scott (2002) aponta que as famílias japonesas estão ficando muito pequenas e os pais com receio de perderem os filhos acabam exagerando nos cuidados e nos presentes, estimulando o espírito consumista insatisfeito dos filhos

O idoso no Brasil é tratado segundo a concepção dos japoneses entrevistados com individualismo e frieza pela familia na maioria dos casos, sendo que em alguns casos as familias que têm dinheito latgam seus idosos em asilos e os outros simplesmente abandonam. Por outro lado alguns consideram que o idoso é tratado bem, principalmente dentro da colônia e da cultura alemã. Também levantam a questão da necessidade do governo ter mais atenção com a questão do idoso.

Moreira (1999) constata que a cultura de um país possui fortes influências na formação familiar e conseqüentemente na maneira como esta lidará com a questão do envelhecimento de seus membros. No caso do Japão percebe-se, segundo a autora, que os mecanismos sociais evitam a saída do idoso de casa para a institutção asilar pública. Portanto toda a estrutura financeira e hierárquica japonesa protege o idoso japonês. Nossos dados apontam que na concepção dos imigrantes japoneses e seus descendentes o idoso no Japão é considerado bem cuidado, porém são levantadas questões como o fato de estarem em asilos e serem um ônus para os familiares em função da longevidade. Indiferente do tipo de cuidados algumas pessoas entrevistadas levantam questões relacionadas ao comportamento das pessoas idosas. Neste sentido referem que os idosos devem continuar a se esforçar e sempre se cuidarem, pois eles têm orgulho e recebem seus direitos de aposentadotia. 
Levantam a questão do respeito assinalando que os filhos dão a tenção aos pais idosos, existindo respeito mútuo entre jovens e idosos. Idosos dependem muito da família em contraponto aos que acham que eles devem ser autônomos. Ainda existe a tradição do filho mais velho ficar encarregado do cuidar dos pais. Neste ponto reforça-se a idéa de que o fllho mais velho, ou flho sucessor é considerado como o bem mais precioso do japonês, pois além de representar a sua continuidade também tepresenta o que Staniford (1073) enuncia como um tipo de aposentadoria na velhice.

Percebe-se que existem diferenças na maneira como o idoso é tratado na cultura japonesa e brasileira, mas de maneira geral as duas culturas possuem "prós e contras" na forma de enfrentar a questão do envelhecimento. O idoso japonês se sente mais seguro e tem todo apoio cultural e político, porém o brasileiro possui uma estrutura familiar que não se obriga a cuidar do idoso e, portanto quando o faz mantém um a relação de carinho forte com o familiar. Nenhuma estrurura é perfeita ou melhor, mas ambas buscam maneiras de se acomodar ao fenômeno do envelhecimento e da longevidade.

Segundo a fala de um dos sujeitos entrevistados "O idoso é tratado como alguém de experiência, capaz de transmiti-la aos jovens". Desta maneira se configura o perfil do papel do idoso na cultura japonesa dentro da Colônia Japonesa de Ivoti.

Os japoneses, que participaran de nossa pesquisa, quando questionados sobre onde preferiam envelhecer responderam em sua grande maioria que gostariam de envelhecer no Brasil, apenas uma pessoa respondeu no Japão. A escolha pelo Brasil sofre algumas ressalvas como a questão da segurança e das melhores condições oferecidas pelo governo japonês. Porém sobressai, para os mais jovens, a idéia de que o Brasil é o seu país e também que aqui construíram suas casas. Uma das pessoas entrevistada, que representa a segunda geração e que tem 44 anos de idade, coloca que o fato que justifica sua escolha pelo Brasil é porque no Japão existe um "sentimento muito frio $\mathrm{cm}$ relação às pessoas, não se tem tempo para crianças e velhos".

De maneira geral percebe-se uma diferença dos ohares dos mais jovens e dos mais velhos. Basicamente, como ressalta Izumi (1973), as duas primeiras gerações tiveram diferenças profundas de acultufação comprometendo significativamente a relação ente pais e filhos.

\section{Referências}

DIÉGUES Júnior, Manuel. Etnias e culturas no Brasil. Rio de Janeiro: Biblioteca do Exército Editora, 1980.

FYORES, Moacir. Histótia do Rio Grande do Sul. Porto Alegre: Editora Nova Dimensão, 1997.

GAUDIOSO, Tomoko Kimura. The woman s rights in the japanese society: its historical perpective. In: Revista da Faculdade de Direito da Universidade Federal do Rio Grande do Sul, Edição Especial - Porto Alegre:UFRGS. Set/2002, p. 130-139.

IZUMI, S. A. estrutura psicológica da colônia japonesa no Brasil, In. H. SAITO; T. MAEYAMA. Assimilação e integração dos japoneses no Brasil, pp. 361-385. Petrópolis: Vozes, 1973. 
KANDAICHI, Haruhiko et alii, org. Nibongo daijiten, Tóquio: ,Kodansha, 1989, p.2021.

MIZUNO, Noriko. Minpon ga kazoku wo kiritsu sbite isseiki. In: Manabi no mori. Sendai: University of Tohoku, 2001. N¹6

MIZUNO, Noriko. A Familia no Japão. Revista da Faculdade de Direito da Universidade Federal do Rio Grande do Sul, Edição Especial - Porto Alegre:UFRGS. Set/ 2002, p. 31-53.

MOREIRA, M. R. L. P. Os idosos japoneses e brasileiros de Vargem Bonita. Humanidades, n. 46, outubro 1999, p. 89-94.

PATRO, Herta Patro. Ivoti: um pontinho no mapa. Ivoti, s.d.

SCHADEN, E. Aculturação de alemães e japoneses no Brasil. In. H. SAITO; T. MAEYAMA. Assimilação e integração dos japoneses no Brasil, pp. 513-521. Petrópolis: Vozes, 1973.

SCOTT, R. P. Envelhecimento e juventude no Japão e no Brasil: idosos, jovens e a problematização da saúde reprodutiva. In. M. C. S. MINAYO e C. E. A. COIMBRA JR. (Orgs.). Antropologia, saúde e envelhecimento, pp. 103-127. Rio de janeiro: FIOCRUZ, 2002.

STANIFORD, P. O background, a estrarégia e a personalidade do imigrante japonês no além-mar. In. H. SAITO; T. MAEYAMA. Assimilação e integração dos japoneses no Brasil, pp. 32-55. Petrópolis: Vozes, 1973. 